\title{
LncRNA WT1-AS over-expression inhibits non-small cell lung cancer cell stemness by down-regulating TGF- $\beta 1$
}

\author{
Xueqin Jiang ${ }^{*}$ (D), Jiong Wang and Lei Fang
}

\begin{abstract}
Background: LncRNA WT1-AS is a recently identified potential tumor suppressor in gastric cancer. This study mainly explored the role of WT1-AS in non-small cell lung cancer (NSCLC).

Methods: WT1-AS and TGF- $\beta 1$ mRNA in two types of tissues of 74 NSCLC patients were detected by performing RT-qPCR experiments. WT1-AS and TGF- $\beta 1$ expression vectors were established using the pcDNA3.1 vector. Protein concentration was measured by BCA assay. Mean values in this study were calculated using the data of three biological replicates of each experiment.

Results: We found that WT1-AS was down-regulated, while TGF- $\beta 1$ was upregulated in NSCLC tissues. Survival analysis showed that low levels of WT1-AS expression predicted poor survival of NSCLC patients. WT1-AS and TGF$\beta 1$ were inversely correlated in NSCLC tissues. Over-expression experiments revealed down-regulated TGF- $\beta 1$ after WT1-AS over-expression, while TGF- $\beta 1$ over-expression failed to affect WT1-AS. WT1-AS over-expression resulted in inhibited cancer cell stemness. TGF- $\beta 1$ over-expression played an opposite role and attenuated the effects of TGF$\beta 1$ over-expression.
\end{abstract}

Conclusion: Therefore, WT1-AS over-expression may inhibit non-small cell lung cancer cell stemness by downregulating TGF- $\beta 1$.

Trial registration: The First Affiliated Hospital of Anhui Medical University Ethics committee approved this study (AHMU20101009).

Keywords: Non-small cell lung cancer, IncRNA WT1-AS, TGF- $\beta 1$, Stemness

\section{Background}

During the past several decades, the incidence of lung cancer continually increased and this disease gradually becomes a leading cause of cancer-related mortalities in many countries of the world, such China and the United States $[1,2]$. In the United States, lung cancer affects more than 1.7 million new cases and causes 0.6 million deaths every year [2]. It is generally believed that more

\footnotetext{
* Correspondence: itgjsoe007596614@126.com

Department of Geriatric Respiratory and Critical Care, the First Affiliated Hospital of Anhui Medical University, No. 218 Jixi Road, Hefei City, Anhui Province 230022, People's Republic of China
}

than $90 \%$ of deaths in cancer patients are caused by cancer metastasis [3], which is common in lung cancer patients by the time of initial diagnosis [4]. Early diagnosis of lung cancer is challengeable due to the lack of sensitive markers $[5,6]$. Therefore, the accurate prognosis may be another option to improve the survival of lung cancer patients.

Non-small-cell lung cancer (NSCLC) is the primary subtype of lung cancer and account for more than $85 \%$ of all lung cancer cases. Altered expression of genetic factors, such as tumor suppressors and oncogenes plays pivotal roles in NSCLC $[7,8]$. Besides that, non-coding

(c) The Author(s). 2020 Open Access This article is licensed under a Creative Commons Attribution 4.0 International License, which permits use, sharing, adaptation, distribution and reproduction in any medium or format, as long as you give appropriate credit to the original author(s) and the source, provide a link to the Creative Commons licence, and indicate if changes were made. The images or other third party material in this article are included in the article's Creative Commons licence, unless indicated otherwise in a credit line to the material. If material is not included in the article's Creative Commons licence and your intended use is not permitted by statutory regulation or exceeds the permitted use, you will need to obtain permission directly from the copyright holder. To view a copy of this licence, visit http://creativecommons.org/licenses/by/4.0/ The Creative Commons Public Domain Dedication waiver (http://creativecommons.org/publicdomain/zero/1.0/) applies to the data made available in this article, unless otherwise stated in a credit line to the data. 
RNAs (ncRNAs), such as its subgroup long ncRNAs (> $200 \mathrm{nt}$, lncRNAs) also participate in human cancer, including NSCLC by regulating the expression of the protein-coding gene [9]. A particular lncRNA, which is named WT1-AS, attracted our attention. This lncRNA plays tumor-suppressive roles in many types of cancer, such as gastric cancer [10], cervical cancer [11] and hepatocellular carcinoma [12], while its role in NSCLC is unknown. It is known that lncRNAs may have similar functions in different types of cancer. Therefore, WT1AS may also have tumor-suppressive roles in NSCLC. The present study was carried out to test this hypothesis.

\section{Methods}

\section{Patients and follow-up}

The research subjects of the present study were 42 male and 32 female NSCLC patients (27 to 69 years, $45.3 \pm$ 6.4 years). All the patients were selected in the First Affiliated Hospital of Anhui Medical University between January 2011 and April 2013. Inclusion criteria: 1) newly diagnosed NSCLC patients by histopathological examinations; 2) patients' therapies were not initiated before admission; 3) patients willing to participate in a 5-year follow-up. Exclusion criteria: 1) recurrent NSCLC (recurrence after treatment); 2) other clinical disorders were observed; 3) any therapies for any diseases were performed within 3 months before admission; 4) who were lost or died of other causes during follow-up. Seventy-four patients included 30 cases of SCC and 44 cases of adenocarcinoma. There were 64 smokers (current or previous) and ten never-smokers. Based on clinical diagnosis data; the 74 patients were grouped into AJCC stage I $(n=12)$, II $(n=24)$, III $(n=20)$ and IV $(n=$ 18). The First Affiliated Hospital of Anhui Medical University Ethics committee approved this study. All the 74 NSCLC patients signed informed consent.

\section{Follow-up}

Patients were followed up for 5 years after admission. Follow-up was performed in a monthly manner through telephone and/or outpatient visit. The survival conditions of each patient were recorded.

\section{Tissues and cells}

Before the initiation of therapies, all patients were subjected to diagnosis using techniques like EBUS-TBNA or endoluminal ultrasound-guided FNA. During diagnosis, both cancer (NSCLC) and non-cancer (within about 2 $\mathrm{cm}$ around tumors) samples were collected from each patient (about $0.1 \mathrm{~g}$ per sample). At least 3 experienced pathologists confirmed all tissues.

NCI-H522 and NCI-H23 human NSCLC cell lines were used in this study. Cells of both cell lines were from ATCC (USA). Cell culture medium was RPMI1640 medium (10\% FBS). Cell culture conditions were $37^{\circ} \mathrm{C}$ and $5 \% \mathrm{CO}_{2}$.

\section{RT-qPCR}

Tissues were ground in liquid nitrogen. Ground tissues, as well as NCI-H522 and NCI-H23 cells, were mixed with Trizol reagent (Invitrogen, USA) to extract total RNAs. Total RNAs were washed with $70 \%$ ethonal, followed by DNase I digestion. The digested RNA samples were used as a template to synthesize cDNA using AMV Reverse Transcriptase (Canvax Biotech, USA). KOD SYBR ${ }^{\circ}$ qPCR Mix (TOYOBO, Japan) was used to prepare all PCR reaction mixtures with $18 \mathrm{~S}$ rRNA or GAPDH as an endogenous control to analyze the expression of WT1-AS and TGF- $\beta 1$. ABI PRISM 7500 qRT-PCR machine (Applied Biosystems, USA) was used to perform all PCR reactions. All qPCR reactions were performed three times. Data were normalized using the $2^{-\Delta \Delta C T}$ method.

\section{Transient transfection}

WT1-AS and TGF- $\beta 1$ expression vectors were established using the pcDNA3.1 vector, which was provided by Sangon (Shanghai, China). Vectors were subjected to Sanger sequencing to make sure correct gene sequences were obtained. All cell transfections were performed using Lipofectamine 3000 (Clontech, USA). Vectors (10 $\mathrm{nM})$ were transfected into $10^{6}$ cells. Following studies were performed using cells collected at $24 \mathrm{~h}$ after transfections. Control (C, non-transfection) and Negative control (NC, empty vector transfection) were included.

\section{Flow cytometry}

NCI-H522 and NCI-H23 cells were harvested at $24 \mathrm{~h}$ after transfections. Cells were subjected to trypsinization. Processed cells were subjected to incubation for $20 \mathrm{~min}$ with CD133-PE or IgG1-PE (Control) antibody (Meltenyi Biotec, Germany) at $4{ }^{\circ} \mathrm{C}$. After that, cells were mixed with PBS. FACS Aria system (BD Immunocytometry Systems, USA) was used to capture signals and signals were analyzed using Cell Quest software (Becton Dickinson Ltd). The percentage of CD133+ cells to all cells was calculated and presented.

\section{Western-blot}

NCI-H522 and NCI-H23 cells were mixed with RIPA solution (Thermo Fisher Scientific) to extract total proteins. Protein concentration was measured by BCA assay (Protein concentration was measured by BCA assay. Total proteins were denatured for $10 \mathrm{~min}$ at $95^{\circ} \mathrm{C}$ and were subjected to electrophoresis using 10\% SDS-PAGE gel with $50 \mu \mathrm{g}$ per lane. After electrophoresis, proteins were transferred to PVDF membranes using a semi dry 
method. Membranes were blocked for $2 \mathrm{~h}$ in $5 \%$ non-fat milk at $22^{\circ} \mathrm{C}$, followed by incubation with GAPDH (rabbit polyclonal, ab9485, 1:1400, Abcam) and TGF- $\beta 1$ (rabbit polyclonal, ab9758, 1:1200; Abcam) primary antibodies for $14 \mathrm{~h}$ or overnight at $4{ }^{\circ} \mathrm{C}$. After that, membranes were further incubated with IgG-HRP secondary antibody (goat anti-human, 1:1000, MBS435036, MyBioSource) for $2 \mathrm{~h}$ at $22^{\circ} \mathrm{C}$. Signals were developed using ECL (Sigma-Aldrich, USA), and signals were processed using Image J v1.46 software.

\section{Statistical analysis}

Mean values in this study were calculated using the data of 3 biological replicates of each experiment. Differences in expression data between NSCLC and non-cancer tissues were analyzed by performing paired $t$-test. One-way ANOVA and Tukey test analyzed differences in cell stemness data and gene expression data among different cell transfection groups. Correlations between WT1-AS and TGF- $\beta 1$ were analyzed by performing linear regression. Based on expression data of WT1-AS in NSCLC tissues, the 74 patients were grouped into high $(n=36)$ and low $(n=38)$ WT1-AS level groups (Youden's index, Graphpad prism six software). K-M method and logrank test were used to plot and compare survival curves. Using the same grouping method, the Chi-squared test was to analyze the correlations between patients' clinical data and WT1-AS and TGF- $\beta 1$ mRNA expression level. Statistically, the significant level was set to $p<0.05$.

\section{Results}

WT1-AS and TGF- $\beta 1$ mRNA showed opposite expression pattern in NSCLC

WT1-AS and TGF- $\beta 1$ mRNA in two types of tissues (NSCLC and non-cancer tissues) of 74 NSCLC patients were detected by performing RT-qPCR experiments. WT1-AS and TGF- $\beta 1$ mRNA expression levels were compared between NSCLC and non-cancer tissues by performing a paired $\mathrm{t}$-test. It was found that the expression levels of WT1-AS were significantly lower (Fig. 1a, $p<0.05$ ), while expression levels of TGF- $\beta 1$ were substantially higher (Fig. $1 \mathrm{~b}, \mathrm{p}<0.05$ ) in NSCLC tissues compared to non-cancer tissues. The chi-squared test showed that expression levels of WT1-AS and TGF$\beta 1$ mRNA were significantly correlated with the clinical stage $(p<0.05)$, but not subtypes of NSCLC $(p>0.05)$ and smoking history $(p>0.05)$.

\section{Low levels of WT1-AS in NSCLC tissues predicted poor survival}

The Patients were grouped, followed the method above. No significant differences in treatment strategies were found between the high and low-level groups. Survival curves were plotted and compared using the aforementioned methods. It was observed that the overall survival rate was significantly lower in low WT1-AS level group than in the high WT1-AS level group (Fig. 2).

\section{WT1-AS down-regulated TGF- $\beta 1$ in NSCLC cell at both mRNA and protein levels}

Results of linear regression showed that, in NSCLC tissues, WT1-AS and TGF- $\beta 1$ expression levels were inversely and significantly correlated (Fig. 3a). In contrast, no promising correlation between the expression levels of WT1-AS and TGF- $\beta 1$ in non-cancer tissues was found (Fig. 3b). To further analyze the relationship between WT1-AS and TGF- $\beta 1$, NCI-H522 and NCI-H23 cells were transfected with WT1-AS and TGF- $\beta 1$ expression vectors. WT1-AS and TGF- $\beta 1$ expression levels were significantly increased at $24 \mathrm{~h}$ after transfections comparing to $\mathrm{C}$ and $\mathrm{NC}$ groups (Fig. $3 \mathrm{c}, p<0.05$ ). In addition, NCI-H522 and NCI-H23 cells with WT1-AS over-expression showed significantly down-regulated TGF- $\beta 1$ at both protein and mRNA levels comparing to two controls (Fig. 3d, $p<0.05$ ). Moreover, NCI-H522 and NCI-H23 cells with TGF- $\beta 1$ over-expression showed no significantly changed expression levels of WT1-AS (Fig. 3e).
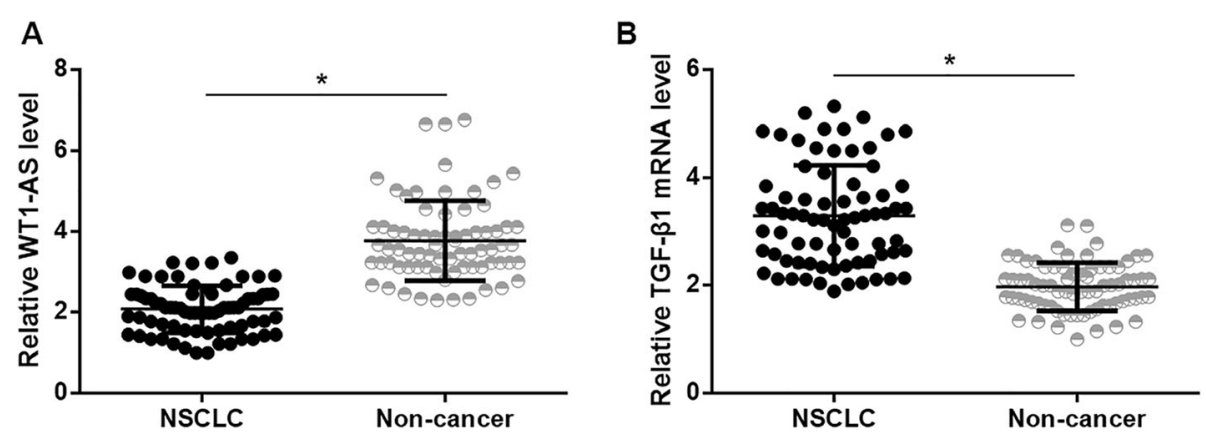

Fig. 1 WT1-AS and TGF- $\beta 1$ mRNA showed opposite expression pattern in NSCLC. Expression data of WT1-AS and TGF- $\beta 1$ were compared between NSCLC and non-cancer tissues by performing paired t test. It was found that WT1-AS was down-regulated (a), while TGF- $\beta 1$ was upregulated (b) in NSCLC tissues than in non-cancer tissues 


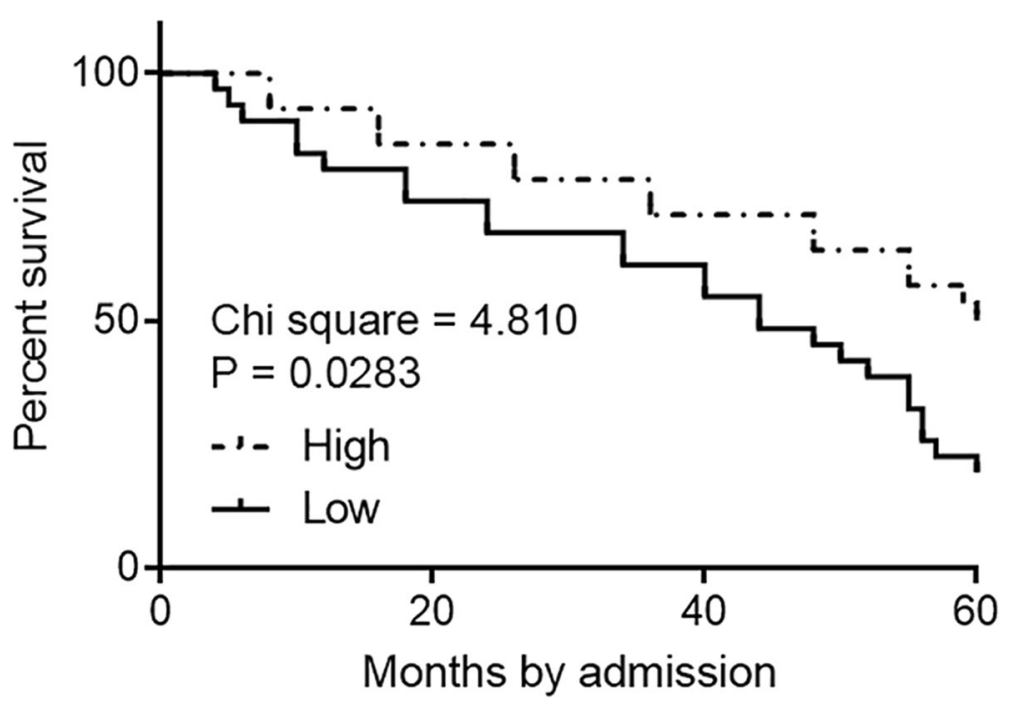

Fig. 2 Low levels of WT1-AS in NSCLC tissues predicted poor survival. Survival analysis was performed to analyze the correlation between expression levels of WT1-AS and survival of NSCLC patients. It was observed that low levels of WT1-AS in NSCLC tissues were accompanied by poor survival

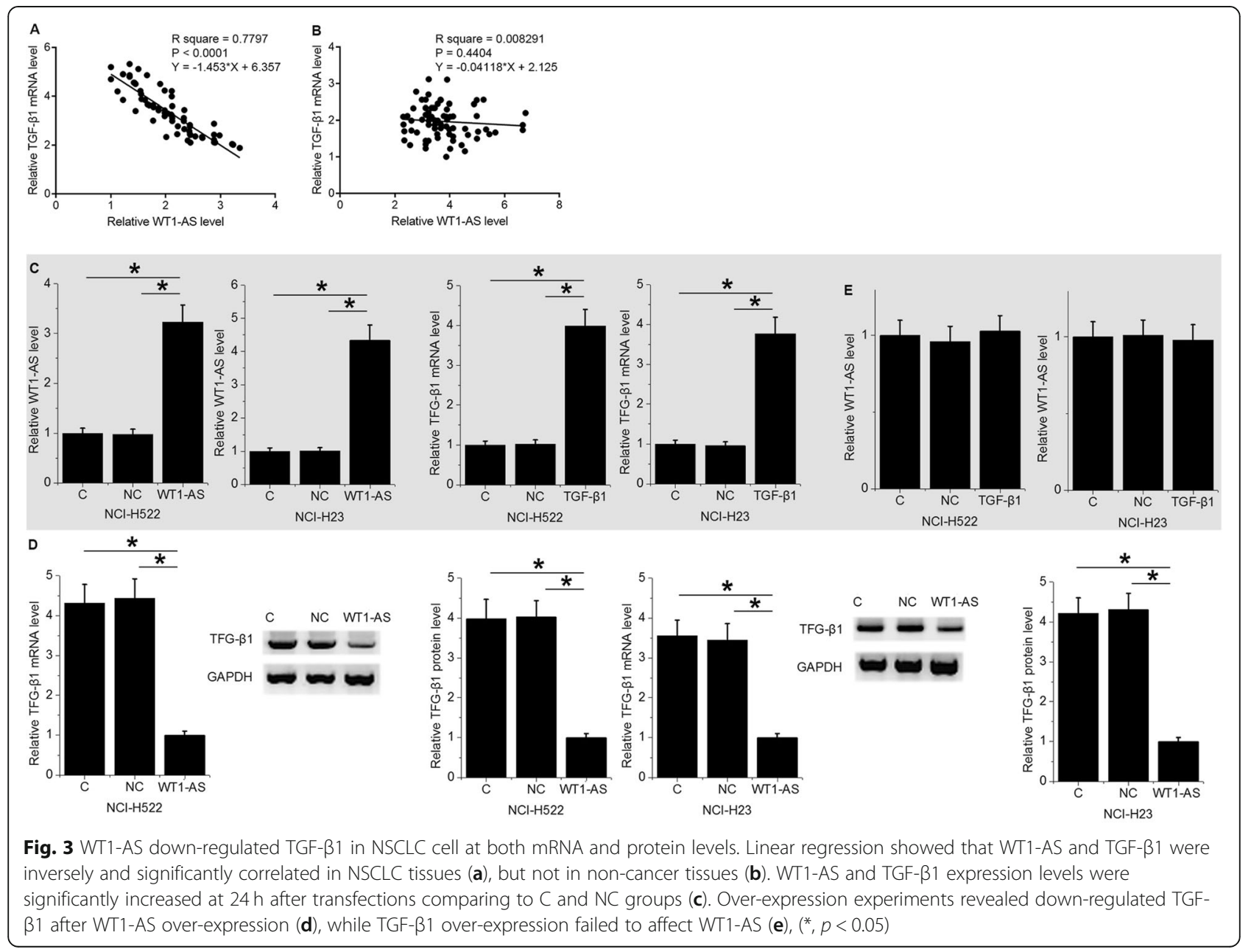


WT1-AS regulated NSCLC cell stemness through TGF- $\beta 1$ Comparing to the $\mathrm{C}$ and $\mathrm{NC}$ groups, WT1-AS overexpression resulted in reduced percentage of CD133+ cells. TGF- $\beta 1$ over-expression resulted in an increased percentage of CD133+ cells. Compared with cells with WT1-AS over-expression alone, cells with both WT1AS and TGF- $\beta 1$ over-expression showed a significantly increased percentage of CD133+ cells (Fig. $4, p<0.05$ ).

\section{Discussion}

We mainly investigated the roles of WT1-AS in NSCLC. We found that WT1-AS was down-regulated in NSCLC and played a tumor-suppressive role in this disease by inhibiting cancer cell stemness. We also proved that WT1-AS might achieve its regulatory roles in cancer cell stemness through the down-regulation of TGF- $\beta 1$.

Previous studies have extensively investigated the roles of WT1-AS in different types of cancers. Du et al. found that WT1-AS was down-regulated in gastric cancer, and the reduced expression levels of WT1-AS were responsible for the increased rate of cancer cell proliferation and invasion [10]. WT1-AS was also down-regulated in cervical cancer, and the over-expression of WT1-AS led to inhibited aggressiveness of cancer cells, indicating that WT1-AS may serve as a target for the treatment of cervical cancer [11]. In hepatocellular carcinoma, WT1-AS down-regulated WT1 to induce the apoptosis of cancer cells [12]. All those previous studies focused on the effects of WT1-AS on different aspects of cancer cell behaviors. Our study focused on cancer stemness, which correlates with cancer cell differentiation and aggressive nature. Stemness is the capacity of cells to perpetuate their lineage and produce differentiated cells. Stemness of a cell determinates its proliferation and regeneration
$[13,14]$. In effect, inhibition of cancer cell stemness results in inhibited cancer recurrence and metastasis [13, 14]. In the present study, we showed that WT1-AS overexpression resulted in decreased NSCLC cell stemness. Our study revealed a new aspect of the function of WT1-AS in cancer biology.

TGF- $\beta$ signaling participates in many aspects of cancer development and progression, such as epithelial-tomesenchymal transition [15], cancer cell proliferation and apoptosis [16], and cancer cell stemness [17]. Our preliminary microarray data revealed an inverse correlation between TGF- $\beta 1$ and WT1-AS across NSCLC tumor specimens (data not shown). Our study confirmed the enhancing effects of TGF- $\beta 1$ over-expression on NSCLC cell stemness. It is known that the function of TGF- $\beta$ signaling in cancer biology can be regulated by specific lncRNAs, such as ANCR and NKILA $[18,19]$. In the present study, we showed that WT1-AS was likely an upstream inhibitor of TGF- $\beta 1$ in the regulation of NSCLC cell stemness. This conclusion is made based on the observation that WT1-AS over-expression led to down-regulated TGF- $\beta 1$ expression (not the other way) and reduced the effects of TGF- $\beta 1$ over-expression on cancer cell invasion and migration (co-transfection experiment). Our data suggest that over-expression of WT1-AS may be a target for the treatment of NSCLC. However, more clinical studies are needed to confirm our hypothesis further. It is worth noting that TGF- $\beta 1$ and WT1-AS were not significantly correlated across normal tissues, indicating that the interaction between TGF- $\beta 1$ and WT1-AS is likely mediated by certain NSCLC-related factors.

It is worth noting that only the CD133 marker was included in this study to measure cell apoptosis, which is a
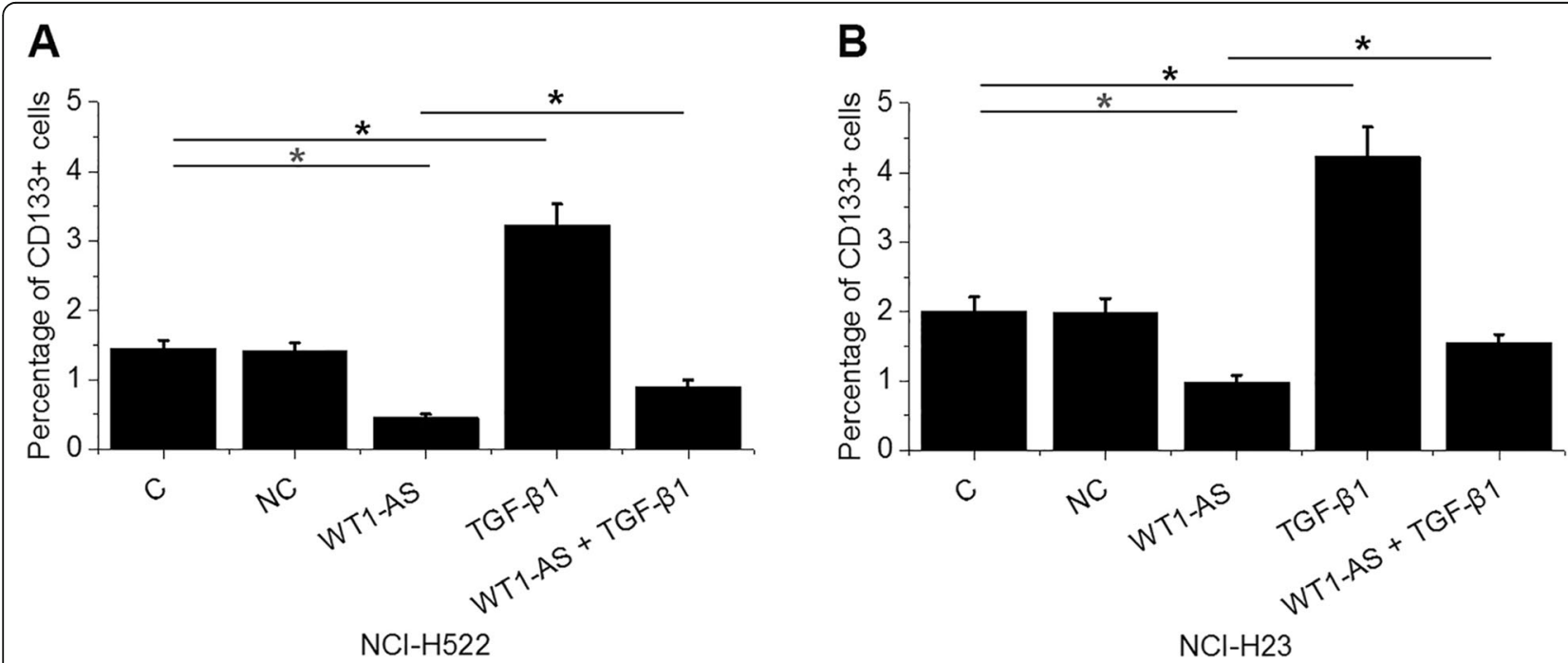

Fig. 4 WT1-AS regulated NSCLC cell stemness through TGF- 31 . WT1-AS over-expression resulted in inhibited cancer cell stemness (reflected by percentage of CD133+ cells) (a). TGF- $\beta 1$ over-expression played an opposite role and attenuated the effects of TGF- $\beta 1$ over-expression $\left({ }^{*}, p<0.05\right)$ (b) 
limitation. Our future studies will consist of more apoptotic markers to further confirm our conclusions.

\section{Conclusion}

In conclusion, WT1-AS was down-regulated in NSCLC, and over-expression of WT1-AS may inhibit the stemness of NSCLC cell stemness by down-regulating TGF- $\beta 1$.

\section{Abbreviation}

NSCLC: Non-small-cell lung cancer

\section{Acknowledgments}

Not applicable.

\section{Ethics approval and consent for participate}

The First Affiliated Hospital of Anhui Medical University Ethics committee approved this study. All procedures performed in studies involving human participants were in accordance with the ethical standards of the institutional research committee and with the 1964 Helsinki declaration and its later amendments or comparable ethical standards. Written informed consent was obtained from all individual participants included in the study.

\section{Authors' contributions}

XQJ study design, data collection and analysis, manuscript editing and written. JW, LF data collection and analysis, manuscript written. All authors have read and approved the manuscript in its current state.

\section{Funding}

None.

\section{Availability of data and materials}

The analyzed data sets generated during the study are available from the corresponding author on reasonable request.

\section{Consent for publication}

Not applicable.

\section{Competing interests}

Author Xueqin Jiang declares that he has no competing interests. Author Jiong Wang declares that he has no competing interests. Author Lei Fang declares that he has no competing interests.

Received: 9 April 2019 Accepted: 13 April 2020

Published online: 29 April 2020

\section{References}

1. Chen W, Zheng R, Baade PD, et al. Cancer statistics in China, 2015. CA Cancer J Clin. 2016;66(2):115-32.

2. Ferlay J, Soerjomataram I, Dikshit R, et al. Cancer incidence and mortality worldwide: sources, methods and major patterns in GLOBOCAN 2012. Int $J$ Cancer. 2015;136(5):E359-86.

3. Gupta GP, Massagué J. Cancer metastasis: building a framework. Cell. 2006; 127(4):679-95.

4. Novello S, Barlesi F, Califano R, et al. Metastatic non-small-cell lung cancer: ESMO clinical practice guidelines for diagnosis, treatment and follow-up. Ann Oncol. 2016;27(suppl_5):v1-v27.

5. Gasparri R, Santonico M, Valentini $C$, et al. Volatile signature for the early diagnosis of lung cancer. J Breath Res. 2016;10(1):016007.

6. Hulbert A, Jusue-Torres I, Stark A, et al. Early detection of lung cancer using DNA promoter hypermethylation in plasma and sputum. Clin Cancer Res. 2017;23(8):1998-2005.

7. Kontic M, Jovanovic D, Ognjanovic S. Hypermethylation of SOX1, RASSF1A, HOXA9, CDH13 and DAPK genes plays a role in NSCLC pathogenesis. J Thorac Oncol. 2018;13(10):1556-0864.

8. Black RC, Khurshid H. NSCLC: an update of driver mutations, their role in pathogenesis and clinical significance. R I Med J. 2015;98(10):25-8.

9. Schmitt AM, Chang HY. Long noncoding RNAs in cancer pathways. Cancer Cell. 2016;29(4):452-63.
10. Du T, Zhang B, Zhang S, et al. Decreased expression of long non-coding RNA WT1-AS promotes cell proliferation and invasion in gastric cancer. Biochim Biophys Acta. 2016;1862(1):12-9.

11. Cui LJ, Nai MM, Zhang K, et al. IncRNA WT1-AS inhibits the aggressiveness of cervical cancer cell via regulating p53 expression via sponging miR-3305p. Cancer Manag Res. 2019;11(11):651-67.

12. Lv L, Chen G, Zhou J, et al. WT1-AS promotes cell apoptosis in hepatocellular carcinoma through down-regulating of WT1. J Exp Clin Cancer Res. 2015;34(1):119.

13. Li Y, Rogoff HA, Keates $S$, et al. Suppression of cancer relapse and metastasis by inhibiting cancer stemness. Proc Natl Acad Sci U S A. 2015;112(6):1839-44.

14. Masuda M, Uno Y, Ohbayashi N, et al. TNIK inhibition abrogates colorectal cancer stemness. Nat Commun. 2016;7:12586.

15. Zhang J, Tian XJ, Xing J. Signal transduction pathways of EMT induced by TGF- $\beta$, SHH, and WNT and their crosstalks. J Clin Med. 2016;5(4):41.

16. Colak S, ten Dijke P. Targeting TGF- $\beta$ signaling in cancer. Trends Cancer. 2017;3(1):56-71.

17. Bellomo C, Caja L, Moustakas A. Transforming growth factor $\beta$ as regulator of cancer stemness and metastasis. Br J Cancer. 2016;115(7):761-9.

18. Li Z, Dong M, Fan D, et al. LnCRNA ANCR down-regulation promotes TGF- $\beta$-induced EMT and metastasis in breast cancer. Oncotarget. 2017; 8(40):67329-43.

19. Wu W, Chen F, Cui $X$, et al. LncRNA NKILA suppresses TGF- $\beta$-induced epithelial-mesenchymal transition by blocking NF-KB signaling in breast cancer. Int J Cancer. 2018;143(9):2213-24.

\section{Publisher's Note}

Springer Nature remains neutral with regard to jurisdictional claims in published maps and institutional affiliations.

Ready to submit your research? Choose BMC and benefit from

- fast, convenient online submission

- thorough peer review by experienced researchers in your field

- rapid publication on acceptance

- support for research data, including large and complex data types

- gold Open Access which fosters wider collaboration and increased citations

- maximum visibility for your research: over $100 \mathrm{M}$ website views per year

At $\mathrm{BMC}$, research is always in progress.

Learn more biomedcentral.com/submission 